\title{
Effect of Kangaroo Mother Care on the Self-esteem of Mothers of Preterm Infants Hospitalized in the Neonatal Intensive Care Unit
}

\author{
Maryam Dehghan ${ }^{1}$, Zahra Kashaninia $^{2 *}$, Firoozeh Sajedi ${ }^{3}$, Pouria Reza Soltani ${ }^{4}$
}

1. Pediatric Nursing, Social Security Organization, Yazd, Iran.

2. Department of Nursing, School of Nursing and Midwifery, Iran University of Medical Sciences, Tehran, Iran.

3. Pediatric Neurorehabilitation Research Center, University of Social Welfare and Rehabilitation Sciences, Tehran, Iran.

4. Department of Statistics, University of Social Welfare and Rehabilitation Sciences, Tehran, Iran.

Citation: Dehghan, M, Kashaninia, Z, Sajedi, F \& Reza Soltani, P 2016, Effect of Kangaroo Mother Care on the self-esteem of mothers of preterm infants hospitalized in the neonatal intensive Care Unit', Journal of Client-Centered Nursing Care, vol. 1, no. 4, pp. 177-182.

Article info:

Received: 05 Jun. 2015

Accepted: 2 Oct. 2015
Keywords:

Preterm infants,

Self-esteem, Mothers,

Kangaroo care

\section{A B S T RA C T}

Background: Preterm newborn birth is usually a challenge for the mother and the family. The mother feels inadequate for the care of her newborn and her self-esteem decreases. In this regard, this study aimed to determine the effect of Kangaroo Mother Care (KMC) on the self-esteem of mothers of preterm newborns.

Methods: This quasi-experimental study was conducted on 46 pairs of mothers and newborns admitted to neonatal intensive care unit (NICU) at the Social Security and Shahid Sadoughi hospitals of Yazd City, Iran. We used available sampling; samples were placed in 2 groups of intervention and control. In the intervention group, the mother held the newborn in an upright position at the middle of her chest to establish skin to skin contact. KMC was performed for 30 minutes each day after feeding, for a period of 4 weeks. However, the control group received the regular process of care from NICU. The mothers' self-esteem in both groups before and after $\mathrm{KMC}$ was evaluated and compared by Rosenberg questionnaire. Data analysis was performed by using the Fisher exact test, paired t test, and independent t-test.

Results: The mean(SD) self-esteem score of the mothers in the intervention group was 25.826(2.480) after the study. However, in the control group, it was 9.609(2.016) $(\mathrm{P}<0.001)$. The average self-esteem scores of mothers in both groups showed a significant difference prior to intervention $(\mathrm{P}=0.014)$; however, in the control group, it was reduced after performing routine nursing cares. Also a significant difference was observed between the self-esteem of mothers in the intervention group before and after intervention $(\mathrm{P}<0.001)$.

Conclusion: Kangaroo care increases the self-esteem of preterm infants' mothers. Therefore, we recommended it to be performed for preterm infants. 


\section{Background}

$\mathrm{P}$

reterm birth is among the most common issues that lead to the hospitalization of newborns in the neonatal intensive care units (NICUs) (Mirlashari, Rassouli \& Gharebagh 2010). On most occasions, hospitalization of preterm newborn is inevitable. Furthermore, a long period hospitalization of newborns in NICU causes family members to experience a sense of loss and disturbance in the emotional relation of the mother with the newborn (Borim Nejad et al. 2011; Gooding 2010). Advances developed in the NICUs have increased the rate of survival for preterm newborns. Despite these advances, the birth of preterm and low weight newborns is the leading cause of death in the first year of life and $85 \%$ of newborns' deaths are due to preterm childbirth.

Therefore, attention to the psychological aspects of preterm childbirth and supporting parents seem important (Akbar Begloo, Valizadeh \& Asadollahi 2009). Preterm newborns and their mothers are often separated when the child is born and physical contact is delayed (Lee \& Bang 2011). This separation generates secretion of hormones in the newborn that affects the child's breathing, heart rate, and body temperature. Also, the birth of such newborns is considered a challenge for the family, especially the mother. Roles, activities, and resourcefulness of the family become imbalanced. Upon the birth of a preterm newborn, the mother feels inadequate for the care of her newborn. Also, the mother's self-esteem (self-trust and content and having positive opinion about one's self) decreases (Moore 2007; Backewell-Sachs \& Gennaro 2004).

In the adverse events of life, people with low self-esteem experience more stress than those with high self-esteem. High self-esteem of mothers is also beneficial for their children (Shahedfar et al. 2009). Mothers of preterm babies feel discontent and lack self-trust. Studies have shown that mothers of premature infants are hesitant in seeing, touching, holding, and embracing their newborns, and thus a negative relationship develops between mother and child (Isler 2007).

Mothers with high self-esteem become less depressed and have a positive attitude toward their children and provide mental and emotional support for them. Mothers' low self-esteem is accompanied with maternal stress (Surkan et al. 2008). Also, low self-esteem is one of the effective factors in the development of depression after childbirth (Amankwaa, Pickler \& Boonmee 2007). It has been shown that mothers who give birth to preterm infants ex- perience more anxiety than mothers of healthy infants, and they are exposed to communication and financial problems and family stresses (Carter \& Mulder 2007). Women as the principal nucleus in the family (women comprise $51 \%$ of the world population) assume basic role in the health of family members and the society at large' Thus, ensuring the mothers' health and happiness is one of the important health issues (Mohammad Yeganeh et al. 2008).

One of the intervention strategies for the care of preterm infants is the Kangaroo care which is recommended to mothers by the therapeutic group (Lightbody 2009; Moore, Anderson \& Bergman 2008). According to the guidelines of WHO, in this type of care, the newborn, naked and wearing headwear or socks is placed between the mother's bosoms under her clothing (Blomqvist \& Nyqvist 2010). Elements of Kangaroo care include skin to skin contact, emotional, physical and educational support, feeding only through breast, early release from hospital, and follow-up (Vakilian 2012).

Through complicated mechanisms, Kangaroo Mother Care (KMC) in addition to its positive effect on the physical growth of the newborn, occasions the newborn's body to conform to the mother's and develops motherinfant affection (Keshavarz \& Bolbol Haghighi 2010a). Moreover, such care is an easy, safe, inexpensive, and reliable method for the newborn and the mother (Arzani et al. 2012). Studies conducted so far in this field have mostly focused on the effect of this type of care on various aspects of the newborn's health; However, a few of those studies have attended to its effect on the mother who is the primary caregiver to her newborn child. Furthermore, in our country no studies have been conducted to determine the effect of this type of intervention on the psychological aspects of mothers of preterm infants. Therefore, the present study was performed with the aim of examining the effect of KMC on the self-esteem of mothers of preterm infants hospitalized in NICUs.

\section{Materials \& Methods}

This research is a quasi-experimental study conducted from January 2013 to June 2013 in the NICUs of Shahid Sadoughi and Social Security hospitals in Yazd, Iran. The sample volume was 23 pairs of mothers and newborns for both groups (Lee \& Bang 2011). The sample size was calculated

$$
n=\frac{2 \sigma_{d}^{2}\left(Z_{1 \alpha / 2}+Z_{1 \beta}\right)^{2}}{\delta^{2}}
$$

by reviewing similar studies and the Cochran's formula: 
With reliability of $\% 95$ and statistical test power of $\% 95$. The inclusion criteria of mothers included non-employment in health centers, treatment centers, or rehabilitation centers; no history of mental-psychological illness or addiction; no history of the infants having been hospitalized in ICUs. In case the mothers were reluctant to continue the study, they had the right to leave the study at any time. The exclusion criteria of mothers comprised inability to stay with newborn, admission to study after their preterm babies were admitted to the study, and diagnosed with incurable diseases (such as duodenal atresia). The inclusion criteria for newborns included weight less than 2500 $\mathrm{g}$, gestational age less than 37 weeks, and the lack of a birth defect, being singleton, and non-use of the mechanical ventilator machine. The exclusion criterion for infants was less than 4 weeks their duration of hospitalization.

After obtaining permission from the Ethics Committee of the University of Welfare and Rehabilitation Sciences, the researcher referred to the NICUs of said hospitals and by employing available sampling method selected mothers and newborns who possessed the inclusion criteria. It should be noted that the researcher acted upon sampling only after explaining the objectives of the study to the mothers. Also, mothers expressed their inclination to participants in the study and filled out their informed consent forms.

First, the sampling was made for the intervention group. For the purpose of preventing the exchange of information between the intervention and the control group, a time block was used. In this way, after the samples in the intervention group reached sufficient number, sampling was ceased for 4 weeks until the mothers participating in the intervention group were released. Then, sampling began for mothers in the control group, with the same method. In total, the sampling for the study took 5 and a half months.

Demographic survey questionnaire for mother, infant, and mothers' self-esteem was conducted through interview by the researcher in the sleeping room of mothers, away from the hubbub of the hospital. Prior to intervention, the researcher provided face to face training on $\mathrm{KMC}$ to the mothers (for 2 days accompanied with question and answer). Also a color booklet on KMC was prepared by the researcher and delivered to the mothers. Considering the heavy workloads in the morning shifts of the hospital, sampling was conducted in the afternoon after 4 PM.

Then, for 4 weeks the KMC was performed, daily in the afternoons, each day for 30 minutes after breastfeeding and changing diapers, while the mother wearing a gown and sitting on a chair in a comfortable position with an angle of 45 to 60 degrees. The KMC was performed in this way that the newborn, naked and wearing a headwear and diaper was placed inside the mother's gown and in direct contact with the mother's chest and abdomen skin (meanwhile, before performing the care, it was requested from the mothers to take a shower). Then, at the end of 4 weeks, the self-esteem questionnaire was filled out through interview by the researcher. Regarding the control group, they only received regular cares according to the hospital's policies. In the control group similar to the intervention group, the questionnaires were filled out under similar conditions before and after the intervention.

Study instruments included the questionnaire on mother's demographic information and general information on the newborn, and also the Rosenberg self-esteem scale (RSES). These questionnaires were filled out through interview with the mothers, and also by referral to the medical history of the mother. RSES was developed in 1965 by Dr Morris Rosenberg. It is a self-esteem measure widely used in social science research. The RSES is designed similar to social survey questionnaires. It is a 10-item Likert-type scale containing 10 general statements answered on a 4-point scale, from "strongly agree" to "agree", "disagree", and "strongly disagree". Five of the items have positively worded statements and 5 have negatively worded ones. The scale measures state self-esteem by asking the respondents to reflect on their current feelings. In this scale, scores were graded from 0 to 3 and the total score of 30 is the highest possible total score. Data were analyzed by using SPSS version 20, through performing independent t-test and paired t-test and the Fisher exact test. P-value less than 0.05 was considered significant.

\section{Results}

In this study, the mean age of the mothers in the intervention group was 26.270 years with a standard deviation of 5.706 and in the control group, it was 28.174 years with a standard deviation of 6.471 . Fifteen $(65.2 \%)$ mothers in the intervention group and $11(47.8 \%)$ members of those in the control group had Caesarian section. Fourteen (60.9\%) newborns in the intervention group and $15(65.2 \%)$ in the control group were male. The average gestational age of the newborns in the intervention group was 29.478 weeks with standard deviation of 1.927 and in the control group, it was 28.826 weeks with standard deviation of 1.899 .

In the intervention group, the average weight of the newborns at the time of birth was $1221.304 \mathrm{~g}$ with standard deviation of 269.832 and in the control group, it was 1096.522 $\mathrm{g}$ with standard deviation of 224.481. The samples in both groups, with regard to confounding variables of gender, gestational age, age of the newborn at the start of intervention, weight at the time of birth, type of delivery, mother's 
Table 1. Comparing the demographic characteristics of mothers of preterm infants hospitalized in the intervention and control groups.

\begin{tabular}{|c|c|c|c|c|c|c|c|c|}
\hline \multirow{2}{*}{ Variants } & \multirow{2}{*}{ Components } & \multicolumn{2}{|c|}{ Intervention } & \multicolumn{2}{|c|}{ Control } & \multicolumn{2}{|c|}{ Total } & \multirow{2}{*}{ P-value } \\
\hline & & No. & $\%$ & No. & $\%$ & No. & $\%$ & \\
\hline Mother's education & $\begin{array}{l}\text { Below diploma } \\
\text { Diploma } \\
\text { Associate degree } \\
\text { Bachelor's degree }\end{array}$ & $\begin{array}{c}8 \\
12 \\
1\end{array}$ & $\begin{array}{l}34.8 \\
52.2 \\
4.3 \\
8.7\end{array}$ & $\begin{array}{c}12 \\
6 \\
2 \\
3\end{array}$ & $\begin{array}{c}52.2 \\
26.1 \\
8.7 \\
13\end{array}$ & $\begin{array}{l}20 \\
18 \\
3 \\
5\end{array}$ & $\begin{array}{c}43.5 \\
39.1 \\
6.5 \\
10.9\end{array}$ & 0.327 \\
\hline Mother's occupation & $\begin{array}{l}\text { Housewife } \\
\text { Employed }\end{array}$ & $\begin{array}{c}23 \\
0\end{array}$ & $\begin{array}{c}100 \\
0\end{array}$ & $\begin{array}{c}21 \\
2\end{array}$ & $\begin{array}{c}91.3 \\
8.7\end{array}$ & $\begin{array}{c}44 \\
2\end{array}$ & $\begin{array}{c}95.7 \\
4.3\end{array}$ & 0.489 \\
\hline Number of abortions & $\begin{array}{c}0 \\
1 \\
2 \\
\geq 3\end{array}$ & $\begin{array}{c}17 \\
4 \\
1 \\
1\end{array}$ & $\begin{array}{c}73.9 \\
17.4 \\
4.3 \\
4.3\end{array}$ & $\begin{array}{l}16 \\
6 \\
0 \\
1\end{array}$ & $\begin{array}{c}69.6 \\
26.1 \\
4.3 \\
0\end{array}$ & $\begin{array}{c}33 \\
10 \\
2 \\
1\end{array}$ & $\begin{array}{l}71.7 \\
21.7 \\
4.3 \\
2.2\end{array}$ & 0.857 \\
\hline Multigravidas & $\begin{array}{c}\text { First child } \\
\text { Second child } \\
\text { Third child or more }\end{array}$ & $\begin{array}{l}15 \\
6 \\
2\end{array}$ & $\begin{array}{l}65.2 \\
26.1 \\
8.7\end{array}$ & $\begin{array}{l}12 \\
5 \\
6\end{array}$ & $\begin{array}{l}52.2 \\
21.7 \\
26.1\end{array}$ & $\begin{array}{c}27 \\
11 \\
8\end{array}$ & $\begin{array}{l}58.7 \\
23.9 \\
17.4\end{array}$ & 0.361 \\
\hline Deceased child & $\begin{array}{l}\text { Yes } \\
\text { No }\end{array}$ & $\begin{array}{c}3 \\
20\end{array}$ & $\begin{array}{l}13 \\
87\end{array}$ & $\begin{array}{c}3 \\
20\end{array}$ & $\begin{array}{l}13 \\
87\end{array}$ & 640 & $\begin{array}{l}13 \\
87\end{array}$ & 1.000 \\
\hline
\end{tabular}

Client-Centered Nursing Care

Table 2. Comparing self-esteem of hospitalized mothers of preterm infants, before and after intervention between 2 groups of intervention and control.

\begin{tabular}{|c|c|c|c|c|c|}
\hline \multirow{2}{*}{ Group } & \multicolumn{2}{|c|}{ Before intervention } & \multicolumn{2}{c|}{ After intervention } & $\begin{array}{c}\text { (P-value) } \\
\text { Paired t-test }\end{array}$ \\
\cline { 2 - 6 } & Mean & SD & Mean & SD & $<0.001$ \\
\hline Intervention & 13.348 & 1.968 & 25.826 & 2.480 & $<0.001$ \\
\hline $\begin{array}{c}\text { (P-value) } \\
\text { Independent t-test }\end{array}$ & 11.913 & 1.832 & 9.609 & 2.016 & \\
\hline
\end{tabular}

Client-Centered Nursing Care

educational level, the parents' occupation, and so on did not have any significant differences (Table 1).

\section{Test results}

The paired t-test showed that the mothers' mean score in the intervention group increased after conclusion of KMC as compared to before its performing $(\mathrm{P}<0.05)$. Also, the average self-esteem of mothers in the control group before and after intervention showed a significant statistical difference. With regard to conventional nursing care, after doing the regular nursing care, the self-esteem of mothers reduced as compared to before intervention (Table 2).

Result of independent $t$ test showed that the average score of the mothers' self-esteem in the intervention group after performing the $\mathrm{KMC}$ increased as compared to the control group $(\mathrm{P}<0.05)$. The average self-esteem of mothers in the intervention group and the control group before intervention had significant statistical difference $(\mathrm{P}=0.014)$ (Table 3$)$.

\section{Discussion}

Present study showed that the average self-esteem of mothers in the intervention group who performed KMC and played an active role in the care of their newborns was higher than the mothers in the control group, i.e. KMC increased the self-esteem of mothers. Jihye L and Kyung Sook (2011) also reached similar conclusions in their own study, stating that after carrying out Kangaroo care, the self-esteem of mothers in the intervention group increased as compared with that in the control group (Lee \& Bang 2011). KMC is recommended as a necessary therapeutic method to promote growth and development of preterm infants, especially their brain development (Ludington- 
Hoe 2013). Blomqvist and Nyqvist (2010) conducted a study entitled 'Swedish mothers' experience of continuous Kangaroo Mother Care". This study showed that mothers considered this model of care as appropriate and have a positive opinion about it. They also stated that this type of mother care provided the support and help they needed. By performing this type of care, they felt calm and secure. Moreover, they expressed that they and their spouses would like to continue KMC at home. The results of the present research were in line with the above mentioned study (Blomqvist \& Nyqvist 2010).

In the current research, during $\mathrm{KMC}$ where the researcher was present, the mothers acknowledged that this method is calming and reduces their stress and increases their independence and effectiveness. Therefore, they welcomed this method, and even they asked several questions from the researcher during the care and received sufficient information on how to continue this method at home.

Mohammadzadeh and colleagues (2011) conducted a study in Mashhad, Iran entitled "Advantages of Kangaroo Mother Care on newborns weighing less than 2000 grams". In this study, they attended to the self-confidence of mothers and the duration of hospitalization of the newborns in the group receiving conventional care. Results of their study showed that the self-confidence of the intervention group was more than that of the control group, and also a reduction of 10 days was achieved for hospitalization of these newborns. They recommended that $\mathrm{KMC}$ be performed in the care of low weight newborns. In fact, parents who spend more time with their newborns, as compared with nurses who have the responsibility to simultaneously care for several newborns, would have more of an occasion to interpret their newborns' discomfiture symptoms and their other needs (Mohammadzadeh et al. 2011).

In a study conducted by Keshavarz and colleagues, the situational anxiety of mothers hospitalized in the Cesarean ward was examined. In the intervention group, skin to skin contact was carried out for 30 minutes. Results of the study showed that the level of mothers' anxiety was significantly lower than that level in the control group. According to the results of this study, researchers stated that the need to use skin to skin contact between the mother and the newborn in the wards after childbirth, especially after Caesarian section, was obvious (Keshavarz et al. 2011). Results of the present study also were consistent with the above study.

Keshavarz and Bolbol Haghighi evaluated the effect of $\mathrm{KMC}$ on the level of pain of mothers who have delivered their child through Caesarean section. They observed that the level of pain of these mothers after Caesarean section was less than those in the control group (Keshavarz \& Bolbol Haghighi 2010b). Considering that most of the studies conducted on KMC were about its effects on the newborns and few studies exist on its effects on mothers, therefore, the results of the present study conformed to the said research.

In conclusion, training and recommending the performance of KMC to mothers, especially those with preterm newborns, can increase mothers' self-esteem, and consequently it will also be effective in the care of these vulnerable newborns. Because, this type of care does not require any especial costs and equipments, we recommend that responsible authorities provide the conditions, facilities, and supports for mothers and the medical staff of NICUs so that this type of care can be performed.

\section{Conflict of Interests}

The authors declared no conflict of interests.

\section{Acknowledgements}

Authors of this study express their appreciation and gratitude to all mothers participating in this study, and also to officials and nurses of Shahid Sadoughi and Social Security hospitals in Yazd City, Iran for their cooperation in conducting this research.

\section{References}

Akbar Begloo, M, Valizadeh, L \& Asadollahi, M 2009, '[Provided Cares for Parents with Hospitalized Premature Infants and its Importance: Nurses' Viewpoint (Persian)]', Nursing $\mathcal{E}$ Midwifery Journal, vol. 4, no. 14, pp.11-7.

Amankwaa, LC, Pickler, RH \& Boonmee, J 2007, 'Maternal responsiveness in mothers of preterm infants', Newborn and Infant Nursing Reviews, vol. 7, no. 1, pp. 25-30.

Arzani, A, Zahedpasha, Y, Ahmadpour Kafiri, S, Khaikhah, F \& Aziznejad, P 2012, '[Kangaroo care effect on self esteem in the mothers of low Birth weight infants (Persian)]', Journal of Babol University of Medical Sciences, vol. 14, no. 3, pp. 52-8.

Bakewell-Sachs, S \& Gennaro, S 2004, 'Parenting the Post-Nicu premature infant', American Journal of Maternal/Child Nursing, vol. 29 , no. 6 , pp. $398-403$

Blomqvist, YT \& Nyqvist, KH 2010, 'Swedish mother's experience of continuous kangaroo mother care', Journal of Clinical Nursing, vol. 20, no. 19-20, pp. 1472-80. 
Borim Nejad, L, Mehrnosh, N, Seyed Fatemi, N \& Haghani, H 2011, '[Maternal Stressor Agents with Premature Infants in Neonatal Intensive Care Units (Persian)]', Iranian Journal of Critical Care Nursing, vol. 4, no. 1, pp. 39-44.

Carter, JD, Mulder, RT \& Darlow, BA 2007, 'Parental stress in the NICU: The influence of personality, psychological, pregnancy and family Factors', Personality and Mental Health, vol. 1, no. 1 , pp. $40-50$.

Gooding, LF 2010, 'Using music Therapy protocols in the treatment of premature infants: An introduction to current practices', Arts in Psychotherapy, vol. 37, no. 3, pp. 211-14.

Isler, A 2007, 'Role of neonatal in initiality the mothers infant relationship in premature infants', Perinatal Journal, vol. 15, no. 1, pp 6-10.

Keshavarz, M \& Bolbol Haghighi, N 2010a, '[Effects of kangaroo contact on some physiological parameters in term neonates and pain score in mothers with cesarean section (Persian)]', Koomesh vol, 11, no. 2, pp. 91-99.

Keshavarz, M \& Bolbol Haghighi, N 2010b, '[Effects of Kangaroo mother care on duration of exclusive breastfeeding and feeding pattern in neonates of mothers who delivered by cesarean section (Persian)]', Medical Science Journal of Islamic Azad University Tehran, Medical Branch, vol. 20, no. 3, pp. 182-8.

Keshavarz, M , Norozi, F, Sayed Fatemi, N \& Haghani, H 2011, '[Effect of Skin to Skin Contact on Maternal State Anxiety in a Cesarean Section Ward (Persian)]', Knowledge \& Health, vol. 5, no. 4, pp. 1-6.

Lee, J \& Bang, KS 2011, 'The effect of kangaroo care on maternal self-esteem and premature infant's physiological stability', Korean Journal of Women Health Nursing, vol. 17, no. 5, pp. 454-62.

Lightbody, T 2009, 'The importance of family-centered care in the NICU', Canadian Nurse, vol. 105, no. 1, pp. 11-20.

Ludington-Hoe, SM 2013, 'Kangaroo care as neonatal therapy', Newborn E Infant Nursing Reviews, vol. 13, no. 2, pp. 73-5.

Mirlashari, J, Rassouli, M \& Gharebagh, AZ 2010, [Nursing care of infant and children (Persian)], $2^{\text {nd }}$ edn, Andishe-Rafi Publisher, Tehran.

Mohammad Yeganeh, L, Bastani, F, Feizi, Z, Agilar Vafaie, M \& Haghani, H 2008, ' [Effect of stress management education on mood and perceived stress among oral contraceptive pill users (Persian)]', Iran Journal of Nursing, vol. 21, no. 53, pp. 63-73.

Mohammadzadeh, A, Farhat, A, Jafarzadeh, M, Hasanzadeh L \& Esmaeli, H 2011, '[Advantages of kangaroo mother care in Less than 2000 grams low birth weight neonates (Persian)]', Medical Journal of Islamic Republic of Iran, vol. 25, no, 1, pp. 11-5.

Moore, ER \& Anderson, GC 2007, ‘Randomized control trial of very early mother infant skin to skin contact and breast feeding status', Journal of Midwifery and Women's Health, vol. 25, no. 2, pp. $16-25$.

Moore, ER, Anderson, GC, Dowswell, T \& Bergman, N 2008, 'Early skin to skin contact for mothers and their healthy infants', Cochrane Database of Systematic Reviews, vol. 62, no. 4, pp. 439- 40.

Shahedifar, N, Sharifian Sani, M, Setareh Forouzan, A \& Biglarian, A 2009, ‘[Exposure To Inter-Parental Physical violence and relationship with self-esteem (Persian)]', Social Welfare, vol. 9, no. 34, pp. 275- 97.
Surkan, PJ, Schnaas, L, Wright, RJ, Tellez-Rojo, MM, LamadridFigueroa, $\mathrm{H}, \mathrm{Hu}, \mathrm{H}$ et al 2008, 'Maternal self-esteem, Exposure to lead and child neurodevelopment', Neurotoxicology, vol. 29, no. 2 , pp. $278-85$.

Vakilian, R 2012, [Package of KMC (Persian)], Company of Tecnology and the art, Tehran. 